\title{
Trend and treatment outcomes of latent tuberculosis infection among migrant persons in Japan: retrospective analysis of Japan tuberculosis surveillance data
}

\author{
Lisa Kawatsu* (1), Kazuhiro Uchimura and Akihiro Ohkado
}

\begin{abstract}
Background: Screening for latent tuberculosis infection (LTBI) among migrant population has become a critical issue for many low tuberculosis (TB) burden countries. Evidence regarding effectiveness of LTBI programs are limited, however, partly because of paucity of national data on treatment outcomes for LTBI. In Japan, notification of LTBI is mandatory, and its treatment outcome is reported as part of Japan's national TB surveillance system. We thus conducted a detailed analysis of LTBI among foreign-born persons, to update the epidemiological trend of newly notified LTBI between 2007 and 2018, and to examine the treatment regimen and outcome of those notified in 2016 and 2017, focusing specifically on the potential risk factors for lost to follow-up.
\end{abstract}

Methods: We extracted and analyzed the data of newly notified LTBI patients from the Japan Tuberculosis Surveillance System to examine the overall trend of notification and by age groups and modes of detection between 2007 and 2018, and the cohort data for treatment regimen and outcomes of foreign-born persons notified with LTBI in 2016 and 2017. Trends and proportions were summarized descriptively, and logistic regression analysis was conducted to identify potential risk factors for lost to follow-up. Comparisons were made with the Japan-born patients where appropriate, using chi-squared tests.

Results: Both the number and proportion of LTBI among foreign-born persons have been constantly increasing, reaching 963 cases in 2018. Cohort analysis of the surveillance data indicated that the proportion of those on shorter regimen was higher among the foreign- than Japan-born patients ( $5.5 \% \mathrm{vs.} 1.8 \%, p<0.001$ ). The proportion of those who have been lost to follow-up and transferred outside of Japan combined was higher among the foreign- than Japan-born patients $(12.0 \%$ vs, $8.2 \%, p<0.001)$. Risk factors for lost to follow-up were being employed on a temporal basis, and job status unknown (adjusted odds ratios 3.11 and 4.09, 95\% confidence intervals 1.347.26 and $1.60-10.48$, respectively).

Conclusions: Migrant population face greater risk of interrupting LTBI treatment, and interventions to improve adherence are a critical component of programmatic management of LTBI. Further studies are needed to explore the cultural and socioeconomic situation in which foreign-born persons undergo LTBI treatment in Japan.

Keywords: Latent tuberculosis infection, Migrants, Trend, Treatment outcome

\footnotetext{
* Correspondence: kawatsu@jata.or.jp

Department of Epidemiology and Clinical Research, The Research Institute of

Tuberculosis, 3-1-24, Matsuyama Kiyose, Tokyo, Japan
}

(c) The Author(s). 2021 Open Access This article is licensed under a Creative Commons Attribution 4.0 International License, which permits use, sharing, adaptation, distribution and reproduction in any medium or format, as long as you give appropriate credit to the original author(s) and the source, provide a link to the Creative Commons licence, and indicate if changes were made. The images or other third party material in this article are included in the article's Creative Commons licence, unless indicated otherwise in a credit line to the material. If material is not included in the article's Creative Commons licence and your intended use is not permitted by statutory regulation or exceeds the permitted use, you will need to obtain permission directly from the copyright holder. To view a copy of this licence, visit http://creativecommons.org/licenses/by/4.0/ The Creative Commons Public Domain Dedication waiver (http://creativecommons.org/publicdomain/zero/1.0/) applies to the data made available in this article, unless otherwise stated in a credit line to the data. 


\section{Background}

Foreign-born populations contribute considerably to both the number and proportion of all tuberculosis (TB) cases, especially in countries with low TB incidence [13]. In Japan as well, which is a TB middle-burden country with a notification rate of 12.3 per 100,000 in 2018 , although the proportion of foreign-born persons out of all TB cases was 9.5\%, that among those aged between 15 and 24 years old has reached $70.8 \%$ in the same year [4]. It has been pointed out that the majority of these $\mathrm{TB}$ cases occurs due to the reactivation of latent tuberculosis infection (LTBI) acquired in their country of origin. As a large proportion of migrants is born in highTB burden countries, where it has been estimated that approximately 26 to $46 \%$ of the population are latently infected with TB $[5,6]$, screening for not only active TB but also LTBI among the migrants, has become a critical issue for many low TB burden countries $(<10$ cases/100, 000 population). In Japan as well, $58.2 \%$ of foreign-born TB patients come from 5 countries in Southeast Asia, with a TB incidence of more than 100 per 100,000 population [4].

Yet in its recently revised guideline, the World Health Organization (WHO) has only conditionally recommended LTBI screening among migrants living in low TB burden countries [7]. The guideline points to the low-quality evidence for the effectiveness and costeffectiveness of LTBI programs in these settings, including challenges in achieving treatment adherence and completion rate. Studies reporting national data on treatment outcomes for LTBI are however limited, due mainly to LTBI not requiring mandatory notification in many countries.

In Japan, however, when a physician diagnoses LTBI and determines that treatment is necessary, he or she is required to notify the local public health center, just as is the case with active TB, under the Infectious Diseases Control Law. Once notified, treatment outcome is evaluated and reported as part of Japan's national TB surveillance system (JTBS) [4]. There is no national guideline that indicates clear priorities for targeted LTBI screening, however, approximately $60 \%$ of notified LTBI patients are detected via contact investigation [4]. Treatment is strongly recommended for selected populations considered to be at a higher risk of developing $\mathrm{TB}$, including people living with HIV/AIDS, silicosis, people on treatment with immunosuppressants, and those who have been recently infected [8].

The authors have previously estimated the treatment outcomes of LTBI notified between 2007 and 2014 - the outcomes were however determined using proxy variables because the JTBS then only evaluated treatment outcome for pulmonary TB [9]. In 2017, the JTBS underwent a system revision, making cohort analysis possible for all types of $\mathrm{TB}$, including extra-pulmonary TB and LTBI, for notifications from 2017 and onward. We thus conducted a detailed analysis of LTBI among foreign-born persons, with two main objectives; firstly to provide a detailed description of the epidemiological trend of newly notified LTBI between 2007 and 2018, and secondly, to examine the treatment regimen and outcome of those notified in 2016 and 2017, focusing specifically on the potential risk factors for lost to follow-up among foreign-born LTBI patients, with the ultimate goal of providing epidemiological evidence which can be used to guide decision-making on screening and testing policies for LTBI among foreign-born persons in Japan.

\section{Methods}

Japan introduced its first electronic surveillance system in 1987, which since then has undergone several major system revisions. Details of the system can be found elsewhere [4]. Briefly, at the end of each year, it produces four sets of data; 1) a list of all active TB and LTBI cases newly notified in that year ("newly notified dataset"), 2) a list of all active TB and LTBI cases registered at the end of the year ("end of year dataset"), 3) a list of active TB and LTBI cases notified in the previous year, with treatment outcomes ("cohort dataset"), and 4) a list of all cases who were de-registered in that year ("de-registered dataset").

\section{Study population and data source}

In order to examine the overall trend of notification and by age groups and modes of detection, we extracted the data of LTBI patients newly notified between 2007 and 2018, from the "newly notified dataset". In order to analyze the treatment regimen and treatment outcomes, we extracted the cohort data of foreign-born LTBI patient who had been notified between 2016 and 2017 from the "cohort dataset".

\section{Data analysis}

Trends and proportions were summarized descriptively, and comparisons were made with the Japan-born patients where appropriate, using chi-squared analysis. Treatment outcomes were analyzed for those who have started treatment, as according to the outcome variables of the JTBS i.e. "treatment success", "died", "treatment failed", "lost to follow-up", "transferred-out", "still on treatment" and "unknown". From the variables that are collected via the surveillance, potential reasons for lost to follow-up were further explored, and logistic regression analysis was conducted to identify risk factors. The crude odds ratio (OR) and adjusted odds ratio (AOR) were reported, with their corresponding 95\% confidence interval and $p$-values. The definitions for the main 
variables can be found in the Annex ( $\mathrm{S} 1$ Appendix). $\mathrm{R}$ version 3.6.3 ( $\mathrm{R}$ Development Core Team, Vienna, Austria) was used for all statistical analyses.

\section{Results}

\section{Trend in LTBI notification}

Figure 1 shows the annual trend of the number of overall LTBI notifications by country of birth, and the proportion of foreign-born persons among the total cases. The number of total LTBI notifications has reached a peak in 2011, and since then it has declined and in the past five years or so, has stabilized around 7000 a year. However, both the number and the proportion of foreign-born LTBI patients have increased steadily, reaching 963 cases in 2018 (13.0\%, 963/7414). Looking at the trend in the notification by age groups, while among the Japan-born patients, the number of notifications has increased only among those aged 55 years old and above, among the foreign-born patients, the number has increased rapidly among all age groups except those aged between 0 and 14 years old (Fig. 2). Regarding the modes of detection, for both Japan and foreign-born patients, the majority were detected via contact investigation over the study period (foreign-born; 80.3\%, and Japan-born; 72.3\%). However, while among the Japanborn, only the number of those detected at hospital has increased, among the foreign-born, the numbers of those detected via contact investigation, routine screening, and at hospital all similarly expressed steady increase (Fig. 3).

\section{LTBI treatment regimen}

From the "cohort dataset", treatment regimen and outcome were available for 12,817 Japan-born and 1418 foreign-born LTBI patients. Of the 12,817 Japan-born and 1418 foreign-born LTBI patients, $96.0 \%(n=12,298)$ and $92.3 \%(n=1309)$ had started their treatment with
INH monotherapy, respectively. Higher proportion of foreign-born than Japan-born patients had started their treatment with RFP monotherapy (5.5\% vs. $1.8 \%, p<$ 0.001) (Table 1).

\section{LTBI treatment outcome}

Treatment outcomes of those who have started treatment, i.e. excluding those whose treatment regimen was recorded as "no treatment", are summarized in Table 2. The overall treatment success was slightly higher among the Japan-born than foreign-born patients $(85.8 \%$ vs. $82.2 \%, p<0.001)$. While the proportion of lost to followup $(8.2 \%$ vs. $8.4 \%, p=0.78)$ were similar among the Japan-and foreign-born patients, the proportion of transferred-out was much higher among the foreignthan Japan-born patients $(8.3 \%$ vs. $1.5 \%, \mathrm{p}<0.001)$. However, the "transfer-out" refers to a move outside the jurisdiction of the public health center to where the patient was initially notified, including both a move to another jurisdiction within Japan, and a move to another country. A closer analysis has revealed that of patients who have transferred-out, while among the Japan-born, 94.8\% (183/193) were transfer-out within Japan, among the foreign-born, $43.0 \%(50 / 116)$ had transferred out of Japan. Considering that treatment outcome of those who have transferred outside of Japan is practically nontraceable, these were re-categorized as lost to follow-up - this had the effect of making lost to follow-up considerably higher among the foreign- than Japan-born patients $(12.0 \%$ vs, $8.2 \%, p<0.001)$.

\section{Risk of lost to follow-up within foreign-born patients}

Proportions of lost to follow-up and those who have transferred out of Japan $(n=167)$, among various sociodemographic characteristics within foreign-born persons are summarized in Table 3.

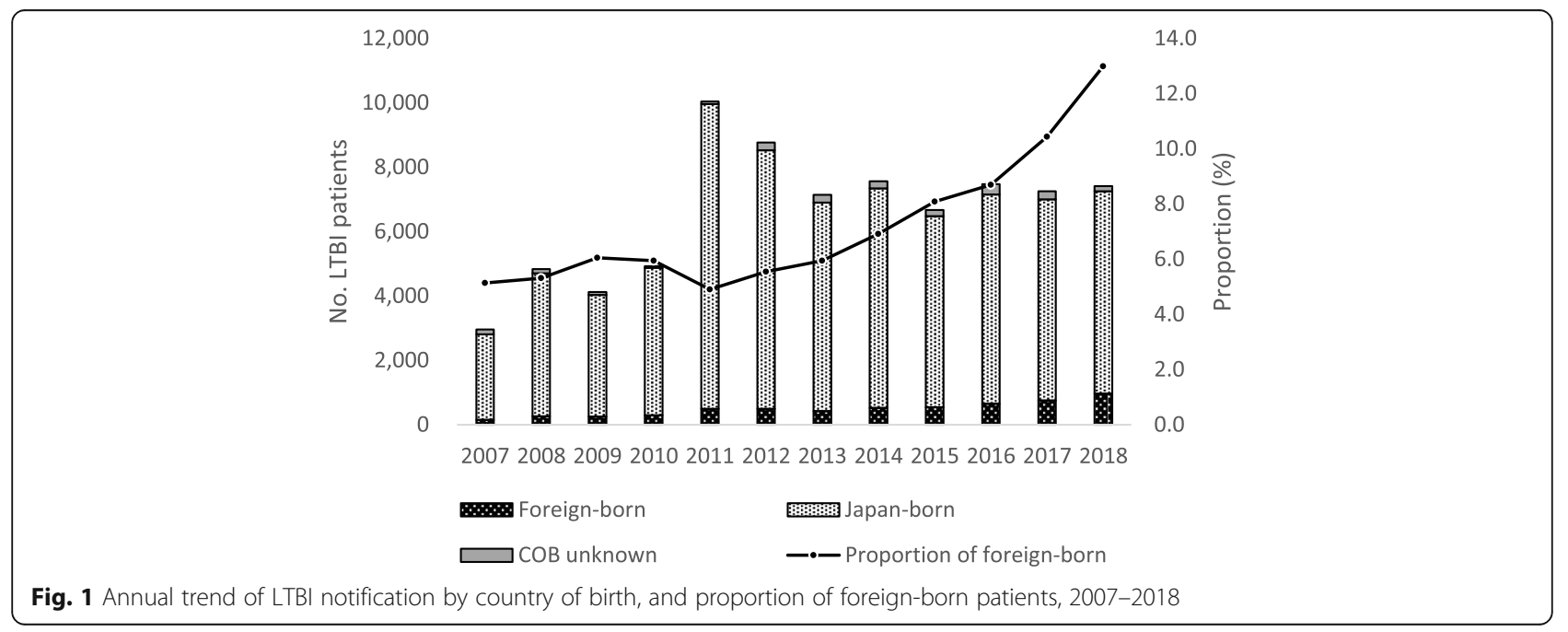



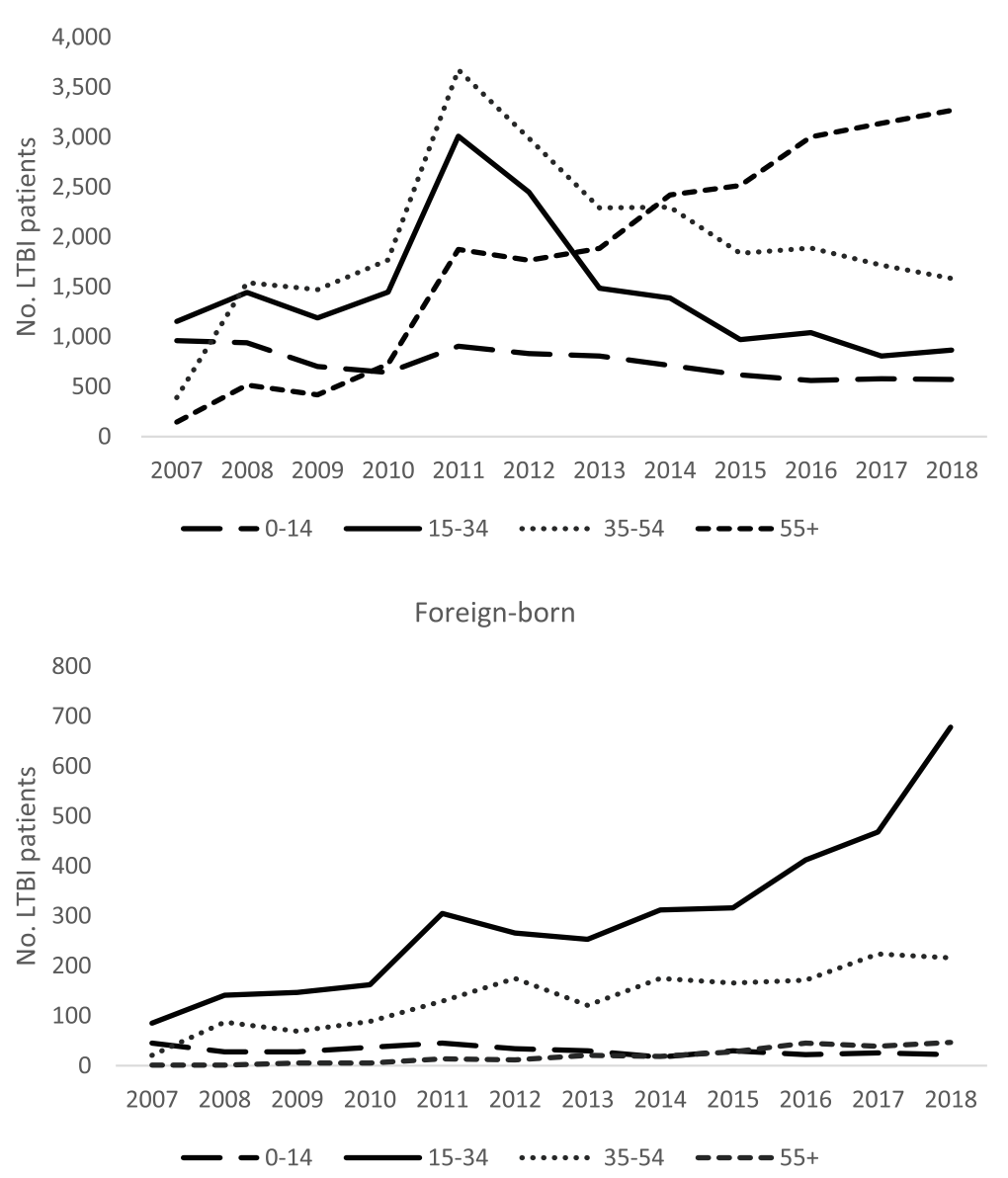

Fig. 2 Trend of LTBI notification by country of birth and age groups, 2007-2018

The results of logistic regression analysis, whereby all of the above characteristics were entered as explanatory variables, are summarized in Table 4.

Variable which remained statistically significant at $P$ value of $<0.05$ was being employed on a temporal basis, and job status unknown.

\section{Discussion}

Our results indicated that LTBI notifications among the foreign-born persons have continued to increase, although this is not surprising considering that the number of foreign-born persons from high TB-burden countries entering Japan have continued to increase [9]. It is certainly possible that foreign-born LTBI patients acquired their infection after immigrating to Japan, however, a molecular-epidemiological study which examined the transmission dynamics of TB among foreign- and Japan-born patients in a large urban area in Japan has suggested otherwise, indicating that most of the foreignborn TB cases were attributable to reactivation of LTBI that were acquired in their home country [10]. Among the Japan-born patients, the rise was mainly seen among the older persons, which can be attributable largely due to the abolition of age limit for LTBI treatment in the national guideline in 2010 [11] and an increasing number of elderly persons being tested for and diagnosed with LTBI before being treated for other medical conditions such as rheumatoid arthritis (i.e. hence LTBI being detected "at hospital"). On the other hand, among the foreign-born persons, the LTBI notifications increased in all age groups except those aged between 0 and 14 years old, and among all modes of detection. Among the Japan-born persons, "routine" screening for LTBI has only really been conducted at selected workplaces, such as among high-risk healthcare workers - however, the constant increase in the notification of LTBI among foreign-born persons via "routine screening" may indicate that increasingly, schools and workplaces are making individual decisions to introduce LTBI screening as part of the routine health-check for foreign-born persons. Indeed, there have been sporadic reports of LTBI screening being conducted as part of medical 


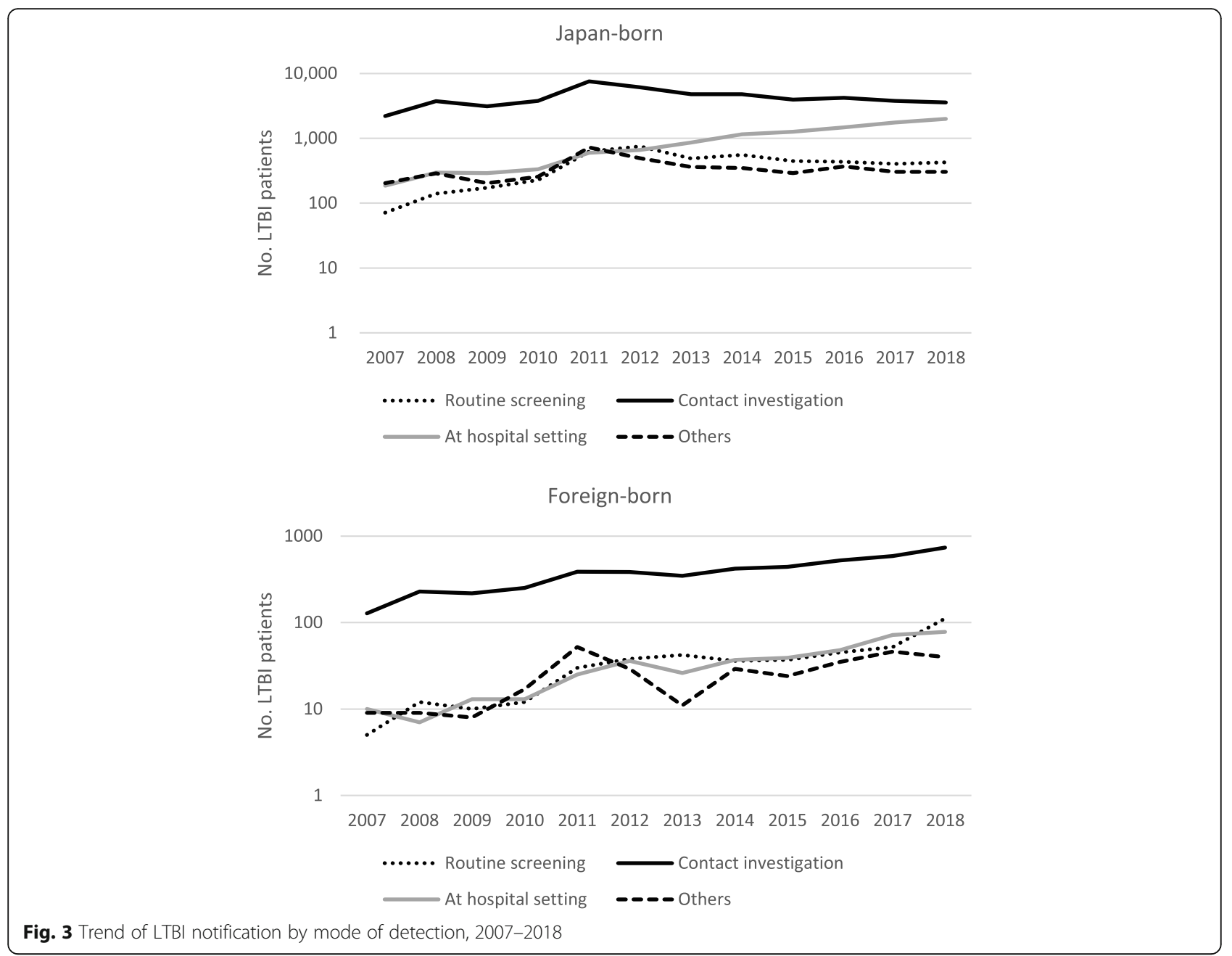

examination upon admissions to universities $[12,13]$. In the absence of a clear national guideline on priorities for LTBI among foreign-born persons in Japan, rigorous studies on effectiveness and cost-effectiveness are urgently needed to determine the most appropriate intervention for case finding of LTBI targeting foreign-born persons in Japan.

Table 1 Treatment regimen of LTBI patients upon registration (2016-2017)

\begin{tabular}{llllll}
\hline & \multicolumn{2}{l}{ Japan-born } & & \multicolumn{2}{c}{ Foreign-born } \\
\cline { 2 - 3 } & $\mathbf{n}$ & \% & & $\mathbf{n}$ & $\%$ \\
\hline INH monotherapy & 12,298 & 96.0 & & 1309 & 92.3 \\
RFP monotherapy & 225 & 1.8 & & 78 & 5.5 \\
No treatment & 235 & 1.8 & & 27 & 1.9 \\
Others $^{\mathbf{a}}$ & 59 & 0.5 & & 4 & 0.3 \\
TOTAL & 12,817 & 100.0 & & 1418 & 100.0 \\
\hline
\end{tabular}

INH isoniazid, RFP rifampicin " excluding "no treatment" - please see Annex (S1 Appendix)
Table 2 Treatment outcomes of LTBI patients (2016-2017), by county of birth

\begin{tabular}{|c|c|c|c|c|}
\hline & \multicolumn{2}{|c|}{ Japan-born } & \multicolumn{2}{|c|}{ Foreign-born } \\
\hline & $\bar{n}$ & $\%$ & $\bar{n}$ & $\%$ \\
\hline Treatment success & 10,798 & 85.8 & 1142 & 82.2 \\
\hline Died & 310 & 2.5 & 1 & 0.1 \\
\hline Failed & 41 & 0.3 & 5 & 0.4 \\
\hline Lost to follow-up & 1026 & 8.2 & 117 & 8.4 \\
\hline Transferred-out & 193 & 1.5 & 116 & 8.3 \\
\hline within Japan & 183 & - & 63 & - \\
\hline outside Japan & 8 & - & 50 & - \\
\hline unknown & 2 & - & 3 & - \\
\hline Still on treatment & 132 & 1.0 & 8 & 0.6 \\
\hline Unknown & 82 & 0.7 & 2 & 0.1 \\
\hline TOTAL & 12,582 & 100.0 & 1391 & 100.0 \\
\hline Lost to follow-up, recategorized ${ }^{a}$ & 1034 & 8.2 & 167 & 12.0 \\
\hline
\end{tabular}


Table 3 Proportions of "lost to follow-up" among various characteristics, foreign-born LTBI patients $(n=1391)$

\begin{tabular}{|c|c|c|c|c|c|}
\hline & Total & LTFU & $\begin{array}{l}\text { Transferred out } \\
\text { of Japan }\end{array}$ & $\begin{array}{l}\text { LTFU + transferred } \\
\text { out of Japan }\end{array}$ & $\begin{array}{l}\% \text { of LTFU + transferred } \\
\text { out of Japan }\end{array}$ \\
\hline \multicolumn{6}{|l|}{ Sex } \\
\hline Male & 665 & 58 & 19 & 77 & 11.6 \\
\hline Female & 726 & 59 & 31 & 90 & 12.4 \\
\hline \multicolumn{6}{|l|}{ Age groups (years) } \\
\hline $0-14$ & 49 & 3 & 2 & 5 & 10.2 \\
\hline $15-19$ & 61 & 4 & 1 & 5 & 8.2 \\
\hline $20-29$ & 630 & 47 & 21 & 68 & 10.8 \\
\hline $30-39$ & 302 & 29 & 17 & 46 & 15.2 \\
\hline $40-49$ & 195 & 21 & 6 & 27 & 13.8 \\
\hline 50 plus & 154 & 13 & 3 & 16 & 10.4 \\
\hline \multicolumn{6}{|l|}{ Job status } \\
\hline Healthcare workers (HCW) & 110 & 10 & 0 & 10 & 9.1 \\
\hline Full-time work, other than HCW & 495 & 28 & 24 & 52 & 10.5 \\
\hline Self-employed & 19 & 1 & 1 & 2 & 10.5 \\
\hline Employed on daily/temporal basis & 114 & 19 & 5 & 24 & 21.1 \\
\hline Houseworkers & 16 & 2 & 0 & 2 & 12.5 \\
\hline Students, high school and above & 432 & 38 & 9 & 47 & 10.9 \\
\hline $\begin{array}{l}\text { Secondary, primary school students, } \\
\text { other children and infants }\end{array}$ & 54 & 4 & 2 & 6 & 11.1 \\
\hline Others and unknown & 67 & 8 & 8 & 16 & 23.9 \\
\hline Unemployed & 84 & 7 & 1 & 8 & 9.5 \\
\hline \multicolumn{6}{|l|}{ Country of Birth } \\
\hline the Philippines & 320 & 33 & 11 & 44 & 13.8 \\
\hline China & 268 & 14 & 18 & 32 & 11.9 \\
\hline Vietnam & 196 & 19 & 8 & 27 & 13.8 \\
\hline Nepal & 194 & 17 & 0 & 17 & 8.8 \\
\hline Indonesia & 66 & 3 & 4 & 7 & 10.6 \\
\hline Myanmar & 56 & 3 & 2 & 5 & 8.9 \\
\hline Others & 291 & 28 & 7 & 35 & 12.0 \\
\hline \multicolumn{6}{|l|}{ Health insurance } \\
\hline National health insurance & 1313 & 107 & 48 & 155 & 11.8 \\
\hline Social Welfare & 18 & 3 & 0 & 3 & 16.7 \\
\hline Others and unknown & 60 & 7 & 2 & 9 & 15.0 \\
\hline \multicolumn{6}{|l|}{ Regimen } \\
\hline INH monotherapy & 1309 & 113 & 48 & 161 & 12.3 \\
\hline RFP monotherapy & 78 & 3 & 2 & 5 & 6.4 \\
\hline Other & 4 & 1 & 0 & 1 & 25.0 \\
\hline \multicolumn{6}{|l|}{ Modes of detection } \\
\hline Routine screening & 95 & 10 & 1 & 11 & 11.6 \\
\hline Contact investigation & 1101 & 89 & 46 & 135 & 12.3 \\
\hline At hospital & 120 & 13 & 3 & 16 & 13.3 \\
\hline Other mass screening & 29 & 1 & 0 & 1 & 3.4 \\
\hline Others & 46 & 4 & 0 & 4 & 8.7 \\
\hline
\end{tabular}


Table 3 Proportions of "lost to follow-up" among various characteristics, foreign-born LTBI patients ( $n=1391)$ (Continued)

\begin{tabular}{|c|c|c|c|c|c|}
\hline & Total & LTFU & $\begin{array}{l}\text { Transferred out } \\
\text { of Japan }\end{array}$ & $\begin{array}{l}\text { LTFU + transferred } \\
\text { out of Japan }\end{array}$ & $\begin{array}{l}\% \text { of LTFU }+ \text { transferred } \\
\text { out of Japan }\end{array}$ \\
\hline \multicolumn{6}{|c|}{ Time between entry to Japan and diagnosis } \\
\hline within 2 years & 381 & 22 & 15 & 37 & 9.7 \\
\hline more than 2 years, within 5 years & 222 & 18 & 15 & 33 & 14.9 \\
\hline more than 5 years, within 10 years & 74 & 10 & 1 & 11 & 14.9 \\
\hline 10 years or more & 199 & 18 & 1 & 19 & 9.5 \\
\hline Unknown & 515 & 49 & 18 & 67 & 13.0 \\
\hline
\end{tabular}

INH isoniazid, RFP rifampicin, LTFU lost to follow-up

The majority of the patients had started LTBI treatment with INH monotherapy. This is understandable considering that, although the WHO guideline recommends both INH monotherapy for 6 months for adults and children in countries of both low and high TB incidence, and RFP monotherapy for 3 to 4 months for both adults and children in countries with low TB incidence [7], the Japanese national guideline recommends INH monotherapy above RFP monotherapy [8]. As to why a higher proportion of foreign-born patients were started with RFP monotherapy - we were unable to find an explanation from our results. We may however speculate that physicians in Japan are more inclined to RFP monotherapy because of their knowledge and awareness regarding higher prevalence of INH resistance among foreign-born TB patients [4].

As for the issue of treatment adherence, to our knowledge, this is the first detailed analysis of LTBI treatment outcome among foreign-born persons at a national level in Japan. Outside of Japan, several systematic reviews on adherence for and outcomes of LTBI treatment have been conducted - for example, a review that was conducted for the WHO 2015 LTBI Guideline has concluded that treatment completion rates varied across different risk groups, ranging from 6 to 94\%, with lower completion rates for prisoners and immigrant [14]. Another study which looked at studies from US and Canada has reported completion rates to be ranging between 22 and $90 \%$ [15], and a more recent review reported rates between 7 to $86 \%$, both for foreign-born person [16]. A meta-analysis that was published in 2016 has estimated the pooled treatment completion rates for migrants to be $14.3 \%$ [17]. The studies which were included in these systematic reviews do, however, vary considerably in terms of sample size, study design, types of immigrant and treatment regimen, and hence caution is required when interpreting the results. Our study results indicate the treatment completion rate for foreignborn persons in Japan is relatively high, compared to other studies included in the abovementioned reviews, albeit not reaching the national target of $85 \%$.
Many studies have also examined the predictors for adherence to LTBI treatment, and in general, have tended to conclude that demographic factors such as age, sex, place of birth and race do not seem to influence completion rate [15]. In our study too, neither sex nor age were conclusive risk factors for lost to follow-up among foreign-born LTBI patients. However, as for age, although not statistically significant, there was a clear tendency for the risk to increase with age. This is quite understandable, as younger children are usually overseen by their guardians and are therefore less likely to become lost to follow-up, as well as for the fact that antituberculosis drugs are unusually better tolerated at younger age. Other socio-economic factors, such as unemployment and lack of health insurance, have previously been associated with failure to complete treatment $[18,19]$ - in our study, none of the foreign-born LTBI patients who had started treatment were reported as "non-insured". Receiving social welfare assistance and having "others and unknown" for insurance status, which could include short-term visitors with private health insurance, were associated with elevated risk but were not statistically significant. As for job status, being employed on a daily or temporal basis, and having "others and unknown" for job status, were both associated with being lost to follow-up. Considering that LTBI treatment is publicly subsidized with minimum out-ofpocket payment, and is unlikely to place a significant financial burden for the patients, being employed on a daily or temporal basis may represent not necessarily poor economic condition but more an unstable lifestyle and greater mobility which are putting patients at risk of becoming lost to follow-up.

As for the length of treatment regimen, while the WHO 2015 Guideline has concluded that longer treatment duration was detrimental to treatment completion, a systematic review that was published a year later has concluded that study results were inconclusive, with some showing better treatment outcomes for shorter regimens using rifampicin, pyrazinamide, rifabutin and/ or $\mathrm{INH}$, than the standard regimen (6 or 9 months of 
Table 4 Risk factors for lost to follow-up and transfer-out combined among foreign-born LTBI patients

\begin{tabular}{|c|c|c|c|c|c|}
\hline & Crude OR & $95 \% \mathrm{Cl}$ & Adjusted OR & $95 \% \mathrm{Cl}$ & $P$ \\
\hline \multicolumn{6}{|l|}{ Sex } \\
\hline Male & Reference & & & & \\
\hline Female & 1.08 & $0.78-1.49$ & 1.16 & $0.81-1.66$ & 0.41 \\
\hline \multicolumn{6}{|l|}{ Age groups (age groups) } \\
\hline $0-14$ & Reference & & & & \\
\hline $15-19$ & 0.79 & $0.21-2.88$ & 2.02 & $0.20-20.39$ & 0.55 \\
\hline $20-29$ & 1.06 & $0.41-2.78$ & 3.06 & $0.24-38.79$ & 0.39 \\
\hline $30-39$ & 1.58 & $0.60-4.20$ & 5.50 & $0.42-71.34$ & 0.19 \\
\hline $40-49$ & 1.41 & $0.51-3.88$ & 5.01 & $0.37-67.1$ & 0.22 \\
\hline 50 plus & 1.02 & $0.35-2.94$ & 3.58 & $0.26-49.37$ & 0.34 \\
\hline \multicolumn{6}{|l|}{ Job status } \\
\hline Healthcare workers (HCW) & Reference & & & & \\
\hline Full-time work, other than HCW & 1.17 & $0.58-2.39$ & 1.29 & $0.60-2.76$ & 0.51 \\
\hline Self-employed & 1.18 & $0.24-5.84$ & 1.21 & $0.23-6.39$ & 0.82 \\
\hline Employed on daily/temporal basis & 2.67 & $1.21-5.88$ & 3.11 & $1.34-7.26$ & $<0.05$ \\
\hline Houseworkers & 1.43 & $0.28-7.20$ & 1.12 & $0.21-5.89$ & 0.89 \\
\hline Students, high school and above & 1.22 & $0.60-2.50$ & 1.98 & $0.85-4.64$ & 0.11 \\
\hline Secondary, primary school students, other children and infants & 1.25 & $0.43-3.64$ & 4.97 & $0.42-58.75$ & 0.20 \\
\hline Unemployed & 1.05 & $0.40-2.79$ & 1.07 & $0.35-3.26$ & 0.90 \\
\hline Others and unknown & 3.14 & $1.33-7.41$ & 4.09 & $1.60-10.48$ & $<0.05$ \\
\hline
\end{tabular}

\section{Country of Birth}

Others

the Philippines

China

Vietnam

Nepal

Indonesia

\section{Regimen}

RFP monotherapy

INH monotherapy

Other

\section{Health insurance}

National health insurance

Social welfare

Others and unknown

Modes of detection

Contact investigation

Routine screening

At hospital

Other mass screening

Others

\section{Reference}

1.17

0.99

1.17

0.70

0.87

Reference

2.05

4.87

Reference

$\begin{array}{lllll}1.49 & 0.43-5.22 & 1.85 & 0.45-7.61 & 0.39 \\ 1.32 & 0.64-2.73 & 1.13 & 0.53-2.43 & 0.76\end{array}$

Reference

$\begin{array}{lllll}0.94 & 0.49-1.80 & 1.09 & 0.54-2.21 & 0.80 \\ 1.10 & 0.63-1.92 & 1.17 & 0.63-2.17 & 0.63 \\ 0.26 & 0.03-1.89 & 0.19 & 0.02-1.47 & 0.11 \\ 0.68 & 0.24-1.93 & 0.64 & 0.22-1.89 & 0.42\end{array}$


Table 4 Risk factors for lost to follow-up and transfer-out combined among foreign-born LTBI patients (Continued)

\begin{tabular}{|c|c|c|c|c|c|}
\hline & Crude OR & $95 \% \mathrm{Cl}$ & Adjusted OR & $95 \% \mathrm{Cl}$ & $P$ \\
\hline \multicolumn{6}{|c|}{ Time between entry to Japan and diagnosis } \\
\hline within 2 years & Reference & & & & \\
\hline more than 2 years, within 5 years & 1.62 & $0.98-2.68$ & 1.69 & $1.00-2.87$ & 0.05 \\
\hline more than 5 years, within 10 years & 1.62 & $0.79-3.35$ & 1.50 & $0.69-3.26$ & 0.31 \\
\hline 10 years or more & 0.98 & $0.55-1.76$ & 0.85 & $0.43-1.68$ & 0.65 \\
\hline
\end{tabular}

INH) while others showing similar completion rates, and also that the studies themselves were too heterogeneous to conduct pooled analysis [16]. In our study, the proportion of lost to follow-up was bigger among those who have started treatment with INH than those with RFP monotherapy (12.3\% vs. $6.4 \%$ ), however, the difference was shown not to be significant in the logistic regression analysis $(p=$ 0.12 ). There could also be various cofounding factors, and a separate survey may be necessary before conclusions can be drawn. It must also be noted that the information regarding treatment regimen is only of that upon notification - in reality, regimen can and do change during the course of the treatment [9], however, neither the change nor the new regimen after change is captured in the JTBS.

It has been reported that one of the major challenges in ensuring adherence especially for LTBI treatment is to overcome the psychological resistance held by patients to take drugs for a non-contagious and nonsymptomatic infection that may never develop into active disease, but which could cause potential adverse effects, and convince them of the potential benefits of prevention [15]. This could be challenging especially when targeting patients who come from culture that is unfamiliar with the concept of screening and prevention [20]. For example, a prospective study that has examined the predictors for non-completion of LTBI treatment has concluded that a perceived risk of progression to active TB is strongly associated with better adherence [21]. However, discussions regarding which factors may influence the construction of such perceived risk and benefit are still inconclusive. One possible factor is the status of being a contact of an active TB patient, and having a close experience with the disease. Indeed, some studies have indicated that contacts tended to have higher completion rates than other population groups [22-24]. In our study, whether or not the patient was a contact of a TB case could be identified from the variable "mode of detection" - those who were detected by contact investigation are obviously case contacts, however, our results indicated that being a contact was not associated with better treatment adherence. This may suggest that being a contact of a TB case alone is a weak motivating factor to adhere to and complete LTBI treatment, at least among foreign-born persons in Japan.
Another potential factor is patient education and counselling - for example, studies from prison have indicated that those who have received education sessions about LTBI prior to being released had higher treatment completion rates post-release, than those who did not [25]. Several studies have shown that well-designed educational intervention using culturally and socially sensitive languages can assist patients make better-informed decisions about the potential risks and benefits of LTBI treatment $[26,27]$. We were unable to assess the possible impact of education as such is not collected in the JTBS. However, numerous studies on adherence support to foreign-born active TB patients in Japan have pointed to the challenge of language [28, 29]. Even today, Japan continues to be a largely mono-cultural society and it is quite common that local healthcare workers only speak Japanese. There is an increasing awareness of the need to improve the language capacity of health services, against the rising number of foreign-born patients in Japan - however, the resources are still very much limited. Under such situation, it is not difficult to imagine that foreign-born patients in Japan are not receiving the appropriate and adequate information that they need to make informed decisions about LTBI and treatment. Studies are needed to explore the most effective information, education, and communication for foreign-born patients regarding LTBI.

Finally, we considered the time between entry to Japan and diagnosis of LTBI as a potential risk factor for lost to follow-up. Compared with those who had been diagnosed within 2 years of arriving to Japan, those who had been in Japan for more than 2 years but less than 5 years had a slightly raised risk of becoming lost to follow-up (adjusted odds ratio 1.69, 95\% confidence interval 1.002.87 ). The risk probably reflects the risk of transferringout of Japan, rather than becoming lost to follow-up in Japan, as the proportion of international transfer-out was the highest among those who had been in Japan for more than 2 years but less than 5 years $(n=15 / 222$, $6.7 \%)$. The reasons are not clear, though this may be related to the duration of permit to stay, which majority of foreign-born students and workers are requested to apply when staying in Japan. The duration of stay depends on the type of permit, however, and it is 
usually 1 year, 3 years or 5 years. In other words, those who are transferring out of Japan may simply be doing so, because their permit to stay is expiring. This brings up another important issue surrounding the continuum of care for LTBI patients across national borders, but the discussions are beyond the scope of this study.

Our study is not without limitations. Firstly, as our sole source of data was the JTBS, we were unable to examine the effects of variables which were not collected in the JTBS, such as frequency of side-effect [30, 31], and alcohol and/or drug dependence [28, 32], which have previously been identified as being potentially detrimental to treatment adherence. Secondly, our study did not take into account those who have become lost to follow-up at various stages in the cascade of care in diagnosis and treatment of LTBI, including those who, despite being eligible, were not tested for LTBI and those, after being diagnosed as LTBI, did not initiate treatment. For example, the previously mentioned metaanalysis has concluded that screening completion rates was the lowest among the migrants (43\%), compared with other populations such as medical personnel $(86.1 \%)$, marginalized persons $(83.3 \%)$ and contacts of active case (79.3\%) [17]. A separate study is probably required to examine the entire cascade of care for LTBI among foreign-born persons in Japan.

\section{Conclusions}

Our study results have added to the growing evidence that migrant population face greater risk of interrupting LTBI treatment. While the WHO updated guideline for LTBI management states that "concerns about adherence should not be a barrier to use of preventive treatment" [7], the authors nevertheless believe that clinical benefit to individual patient and the success of control programs are subject to completion of LTBI treatment, and hence interventions to improve adherence are a critical component of programmatic management of LTBI.

As previous studies have already shown, efforts to establish a "one-size fits-all" approach to improve adherence to LTBI treatment are probably not likely to succeed. Our results have indicated risk factors for lost to follow-up, some of which were potentially unique to Japan. On the other hand, we have also pointed to the need for a further, in-depth study to explore the socioeconomic and cultural situation in which foreign-born persons initiate LTBI treatment in Japan. Whatever the target population, sharing the experience of trying to understand the population and identifying potential barriers, and of innovative approaches to improving adherence can be beneficial to the global effort in tackling LTBI.

\section{Supplementary Information}

The online version contains supplementary material available at https://doi. org/10.1186/s12879-020-05712-1.

Additional file 1. Definitions of selected variable from the Japan Tuberculosis Surveillance system.

Additional file 2. Annual trend of LTBI notification by country of birth and age groups, 2007-2018. Excel file (.xls) showing the number of LTBI notifications by country of birth and age groups.

Additional file 3. Trend of LTBI notification by mode of detection, 2007-2018. Excel file (.xIs) showing the number of LTBI notifications by mode of detection, 2007-2018.

\section{Abbreviations}

INH: Isoniazid; JTBS: Japan Tuberculosis Surveillance; LTBI: Latent tuberculosis infection; RFP: Rifampicin; TB: Tuberculosis

\section{Acknowledgements}

The authors would like to acknowledge all those who contributed to notifying and registering information on TB patients in Japan, including physicians, public health nurses, microbiologists and administrative staff.

\section{Authors' contributions}

LK and UK initiated and designed the study. LK and UK analyzed the data, LK was responsible for writing up, and all (LK, UK, AO) were involved in the discussion of the results. All authors have read and approved the final manuscript.

\section{Funding}

The study was supported by JSPS Grants-in-Aids for Scientific Research (C), grant number: 20 K10491. The funders had no role in study design, data collection and analysis, decision to publish, or preparation of the manuscript.

Availability of data and materials

All data generated or analysed during this study are included in this published article [and its supplementary information files].

Ethics approval and consent to participate

Ethical clearance obtained from the Institution al Review Board of the Research Institute of Tuberculosis (reference number RIT/IRB 2020-08). Informed consent as deemed unnecessary as the JTBS data does not include case identifiers, as according to the Ethical Guidelines for Epidemiological Research established by Ministry of Education, Culture, Sports, Science and Technology and Ministry of Health, Labour and Welfare of Japan.

\section{Consent for publication}

Not applicable.

\section{Competing interests}

The authors declare that they have no competing interests.

Received: 16 July 2020 Accepted: 15 December 2020

Published online: 09 January 2021

\section{References}

1. European Centre for Disease Prevention and Control (ECDC)/World Health Organization Regional Office for Europe. Tuberculosis surveillance and monitoring in Europe 2018-2016 data. Stockholm: ECDC; 2018. Available from: https://ecdc.europa.eu/sites/portal/files/documents/ecdc-tuberculosissurveillance-monitoring-Europe-2018-19mar2018.pdf WHO. Accessed 3 Apr 2020.

2. Centers for Disease Control and Prevention (CDC). Reported Tuberculosis in the United States, 2017. Atlanta, GA: US Department of health and human services, CDC; 2018.

3. Toms C, Stapledon R, Coulter C, Douglas P. The National Tuberculosis Advisory Committee. Tuberculosis notifications in Australia, 2014. Commun Dis Intell. 2017:41:3. 
4. Tuberculosis Surveillance Center. Tuberculosis in Japan - annual report 2019. Tokyo: Department of Epidemiology and Clinical Research, the Research Institute of Tuberculosis; 2019.

5. Pareek M, Baussano I, Abubakar I, Dye C, Lalvani A. Evaluation of immigrant tuberculosis screening in industrialized countries. Emerg Infect Dis. 2012; 18(9):1422-9. https://doi.org/10.3201/eid1809.120128.

6. Campbell JR, Chen W, Johnston J, Cook V, Elwood K, Krot J, Marra F. Latent tuberculosis infection screening in immigrants to low-incidence countries: a meta-analysis. Mol Diagn Ther. 2015;19(2):107-17. https://doi.org/10.1007/ s40291-015-0135-6.

7. Latent tuberculosis infection. updated and consolidated guidelines for programmatic management. Geneva: World Health Organization; 2018. License: CC BY-NC-SA 3.0 IGO.

8. The Prevention Committee and the Treatment Committee of the Japanese Society for Tuberculosis. Treatment Guideline on LTBI. Kekkaku. 2013;88:497512.

9. Ministry of Justice. Annual Report on Statistics on Legal Migrants, 2019. http://www.moj.go.jp/housei/toukei/toukei_ichiran_nyukan.html.

10. Murase Y, Ohkado A, Watanabe Y, Kaguraoka S, Ishihara K, Homareda C, Uchimura K, Maeda S, Takii T, Ishikawa N. Transmission dynamics of mycobacterium tuberculosis between foreign-nationals and Japanese tuberculosis patients living in Shinjuku-City, Tokyo. Japan Kekkaku. 2017;92: 431-9.

11. Kawatsu L, Uchimura K, Ohkado A. Trend and treatment status of latent tuberculosis infection patients in Japan - analysis of Japan TB surveillance data. PLoS One. 2017;12(11):e0186588. https://doi.org/10.1371/journal.pone. 0186588.

12. Tanaka Y, Suzuki M. Gaikokujin ryugakusei no senzaisei kekkaku kansenshou ni taisuru IGRA to kyoubu $X$ sen niyoru kenko kanri (Medical examination via IGRA and chest X-ray for foreign-born students). Campus Health. 2018; 55(1):462-4 In Japanese.

13. Nishimura T, Mori M. Gaikokujin ryugakusei no kekkaku kansen chousa (screening for TB infection among foreign-born students). Bull Keio University Health Center. 2019;37(1):35-9 In Japanese.

14. Getahun H, Matteelli A, Abubaker I, Abdel Aziz M, Baddeley A, Barreira D, et al. Management of latent mycobacterium tuberculosis infection: WHO guidelines for low tuberculosis burden countries. European Respir J. 2015; 46(6):1563-76. https://doi.org/10.1183/13993003.01245-2015.

15. Hirsch-Moverman Y, Daftary A, Franks J, Colson P. Adherence to treatment for latent tuberculosis infection: systematic review of studies in the US and Canada. Int J Tuberc Lung Dis. 2008;12(11):1235-54.

16. Sandgren A, Noordegraaf-Shouten MV, van Kessel F, Stuuman A, OordtSpeets A and van der Werf MS. Initiation and completion rates for latent tuberculosis infection treatment: a systematic review. BMC Infect Dis. 2016; 16:204. DOI: https://doi.org/10.1186/s12879-016-1550y.

17. Alsdurf H, Hill PC, Metteelli A, Getahun H, Menzies D. The cascade of care in diagnosis and treatment of latent tuberculosis infection: a systematic review and meta-analysis. Lancet Infect Dis. 2016;16(11):1269-78. https://doi.org/10. 1016/S1473-3099(16)30216-X

18. Nyamathi AM, Christiani A, Nahid P, Gregerson P, Leake B. A randomized controlled trial of two treatment program for homeless adults with latent tuberculosis infection. Int J Tuberc Lung Dis. 2006;10:775-82.

19. Lardizabal A, Passannante M, Kojakali F, Hayden C, Reichman LB. Enhancement of treatment completion for latent tuberculosis infection with 4 months of rifampin. Chest. 2006;130:1715-7.

20. Spruijt I, Haile DT, Erkens C, van den Hof S, Goosen S, ten Kate A, Tshome H, Karels M, Koenders M, Suurmond J. Strategies to reach and motivate migrant communities at high risk for TB to participate in a latent tuberculosis infection screening program: a community-engaged, mixed methods study among Eritreans. BMC Public Health. 2020;20:315. https://doi. org/10.1186/s12889-020-8390-9.

21. Shieh FK, Snyder G, Horsburgh CR, Bernado J, Murphy C, Saukkonen JJ. Predicting non-completion of treatment for latent Tuberculous infection. A prospective survey. Am J Respir Crit Care Med. 2006;174:717-21.

22. Center for Disease Control and Prevention. Transmission of mycobacterium tuberculosis in a high-school and school-based supervision of an isoniazidrifapentine regimen for preventing tuberculosis - Colorado, 2011-2012. MMWR Morb Mortal Wkly Rep. 2013;62:805-9.

23. Sloot R, van der Loeff MF S, Kouw PM, Borgdorff MW. Yield of tuberculosis contact investigation in Amsterdam: opportunities for improvement. Eur Respir J. 2014;44:714-24.
24. Reichler MR, Reves R, Bur S, Ford J, Thompson V, Mangura B. Treatment of latent tuberculosis infection in contacts in new tuberculosis cases in the United States. South Med J. 2002;95:414-20.

25. White MC, Tulsky JP, Menedez E, Goldenson J, Kawamura LM. Incidence of TB in inmates with latent TB infection: 5 year follow-up. Am J Prev Med. 2005:29:295-301.

26. Kim DY, Rizdon R, Giles B, Mireles T, Garrity K, Hatchcock AL, Crowder D, Jackson R, Taylor Z. A no-name tuberculosis tracking system. Am J Public Health. 2003;93:1637-9.

27. Goldberg SV, Wallace J, Jackson JC, Cahulk CP, Nolan CM. Cultural case management of latent tuberculosis infection. Int J Tuberc Lung Dis. 2004;8: $76-82$.

28. Shigeto E. Nihon no kekkakuchiryou niokeru shomondai (issues in treatment of tuberculosis in Japan). Kekkaku. 2018;93:563-8 In Japanese.

29. Nagata Y, Takayanagi K, Yano R, Sawada T, Morita N, Murakami K, Takasaki J. Utilization of medical interpreters for tuberculosis patients in Japan: a questionnaire survey. Kekkaku. 2020;95:41-6.

30. Ailinger RL, Dear MR. Adherence to tuberculosis preventive therapy among Latino immigrants. Public Health Nurs. 1998;15:19-24.

31. LoBue A, Moser S. Use of isoniazid for latent tuberculosis infection in a public health clinic. Am J Respir Crit Care Med. 2003;168:443-7.

32. Lobato N, Reves R, Jasmar M, Grabau C, Bock N, Shang N, et al. Adverse events and treatment completion for latent tuberculosis in jail inmates and homeless persons. Chest. 2005;127:1296-303.

\section{Publisher's Note}

Springer Nature remains neutral with regard to jurisdictional claims in published maps and institutional affiliations.

Ready to submit your research? Choose BMC and benefit from:

- fast, convenient online submission

- thorough peer review by experienced researchers in your field

- rapid publication on acceptance

- support for research data, including large and complex data types

- gold Open Access which fosters wider collaboration and increased citations

- maximum visibility for your research: over $100 \mathrm{M}$ website views per year

At BMC, research is always in progress.

Learn more biomedcentral.com/submissions 